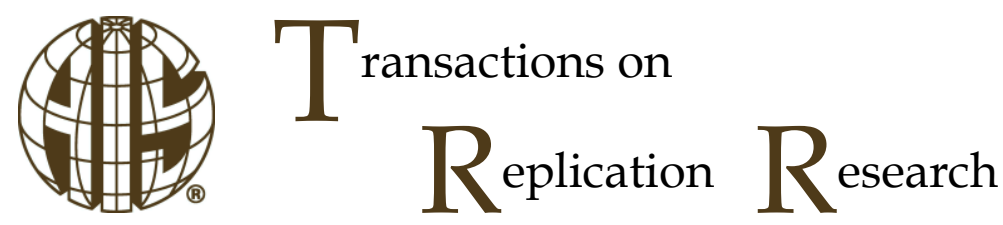

\title{
Time flies when you are having fun: Cognitive Absorption and Beliefs about Social Media Usage
}

\author{
Ana Lucia de Queiroz Tourinho \\ Department of quantitative methods and \\ information technology \\ Fundação Getulio Vargas - EAESP \\ analucia.tourinho@gmail.com
}

\author{
Bruna Miyuki Kasuya de Oliveira \\ Department of quantitative methods and \\ information technology \\ Fundação Getulio Vargas - EAESP \\ brunamiyuki@gmail.com
}

\begin{abstract}
:
The purpose of this study was to do a methodological replication of Agarwal \& Karahanna (2000), in the context of social media. The original work describes a construct labeled 'cognitive absorption' (CA) having a theoretical base derived from three inter-related areas of research: the personality trait dimension of absorption, the state of flow, and the notion of cognitive engagement. Regarding the methodological replication process, we adapted the original instrument to the context of social media and collected data from 326 students. Following the same procedures used by Agarwal \& Karahanna (2000), we used Partial Least Squares (PLS) to analyze the data and found results that supported the ideas advanced in their study, although we also identified some differences concerning perceived usefulness, self-efficacy, and personal innovativeness. The differences we found seem to be entirely associated with the context of social media. The level of experience in using technology is likely explained by the fact that the exposure to technology is much more significant today than 16 years ago, technology has become part of the daily routine of individuals, where social media is one of the most widely used.
\end{abstract}

Keywords: User's beliefs, cognitive absorption, social media, user behavior toward social media

Both authors contributed equally to the paper and are listed in alphabetical order.

The manuscript was received 04/05/2017 and was with the authors 9 months for two revisions. 


\section{Introduction}

This research aims to replicate the original study conducted by Agarwal and Karahanna in 2000, who described cognitive absorption (CA) as a multidimensional construct comprising five dimensions: temporal dissociation, focused immersion, heightened enjoyment, control, and curiosity. The theoretical bases of CA have grounded in three studies: a trait dimension called absorption (Tellegen, 1982; Tellegen and Atkinson, 1974), the state of flow (Csikszentmihalyi, 1990), and the notion of cognitive engagement (Webster and Ho, 1997). According to Agarwal and Karahanna (2000), CA is an intrinsic motivation variable, defined as a state in which there is a broad involvement with software. In the proposed nomological net shown in figure $1, C A$ is posited as an important antecedent for technology use behavior, mediated by perceived usefulness and ease of use, where the perception of ease of use influences the perceived usefulness (Agarwal and Karahanna, 2000).

Even after almost two decades, the original paper by Agarwal and Karahanna (2000) is still heavily cited in the IS field, demonstrating that the CA construct remains up-to-date and a pivotal antecedent to explain beliefs about information technology. Searching the EBSCO's Business Source Complete (11/2017) more than 340 studies cite the original work. Among those, there is a key research that explicitly applied the CA construct and found that CA has a significant impact on users behavior towards information technology (Chandra, Srivastava, \& Theng, 2012). In their study, Saade and Bahli (2005) for instance explored CA to understand students intention to use Internet-based learning system and found that CA impacts the acceptance of online learning systems (Saadé \& Bahli, 2005). In Chandra et al. (2012), the CA construct was also used with user trust. They aimed at proposing a nomological net for adaptive use intention of virtual worlds for workplace collaborations, and it revealed a similarly significant relation between CA and trust (Chandra, Srivastava, \& Theng, 2012). More recently, Midha (2016) replicated the Agarwal and Karahanna (2000) study in the context of Second Life, and his findings supported cognitive absorption as a construct that positively influences perceived ease of use and perceived usefulness (Midha, 2016).

Whereas in the original study the Web was the target technology used as the research context, in the present study we focused on social media since it has currently been one of the most pervasive technologies in people's lives. Differently from the Web scenario in 2000 when accessing the Web was not widely available, today the social media provides that to people having different profiles, at any time and any place. With that being so, the replication in a social media context becomes entirely relevant. Firms have used social media to enhance brand popularity (De Vries, Gensler, \& Leeflang, 2012), increase sales (Agnihotri, Kothandaraman, Kashyap, \& Singh, 2012), generate social support for consumers (Ali, 2011), and other generating-value purposes (Hajli, 2014). Besides, individuals networking through social media delivers shared values that lead to a positive impact on virtual communities trust (Wu, Chen, \& Chung, 2010). Therefore, our goal is to investigate the boundaries of the original work by applying a methodological replication approach to the social media context.

Facebook, Linkedln, Instagram, and other social network sites are increasingly popular among individuals from different backgrounds. Such individuals are using that technology to become socially engaged and to socially interact with their online and offline social network (Boyd and Ellison, 2007; Pfeil, Arjan, and Zaphiris, 2009). The use of social technologies is expanding not only in users but also in the number of time people spent on interacting with the social networking. According to Published by the Pew Research Center, the Social Media Update (2016) states that Facebook remains the most popular social media platform. Out of $86 \%$ of Americans currently using the Internet, $79 \%$ are Facebook users, followed by $32 \%$ for Instagram, 31\% for Pinterest, 29\% for Linkedln and 24\% for Twitter. Those numbers have been annually growing, embracing male and female users, from urban or rural areas, various age groups and education background. Social media empowers people for it enables them to perform several activities online. Reading the news, enhancing professional network on Linkedln, embracing social causes and enrolling in events (Duggan, Ellison, Lampe, Lenhart, \& Madden, 2015; Duggan, Page, \& Manager, 2016). Such facts endorsed our belief that social media has indeed become a thought-provoking context in which to study CA.

Figure 1 presents the nomological net proposed by Agarwal and Karahanna (2000). We are following the same methodological procedures of the original study. 


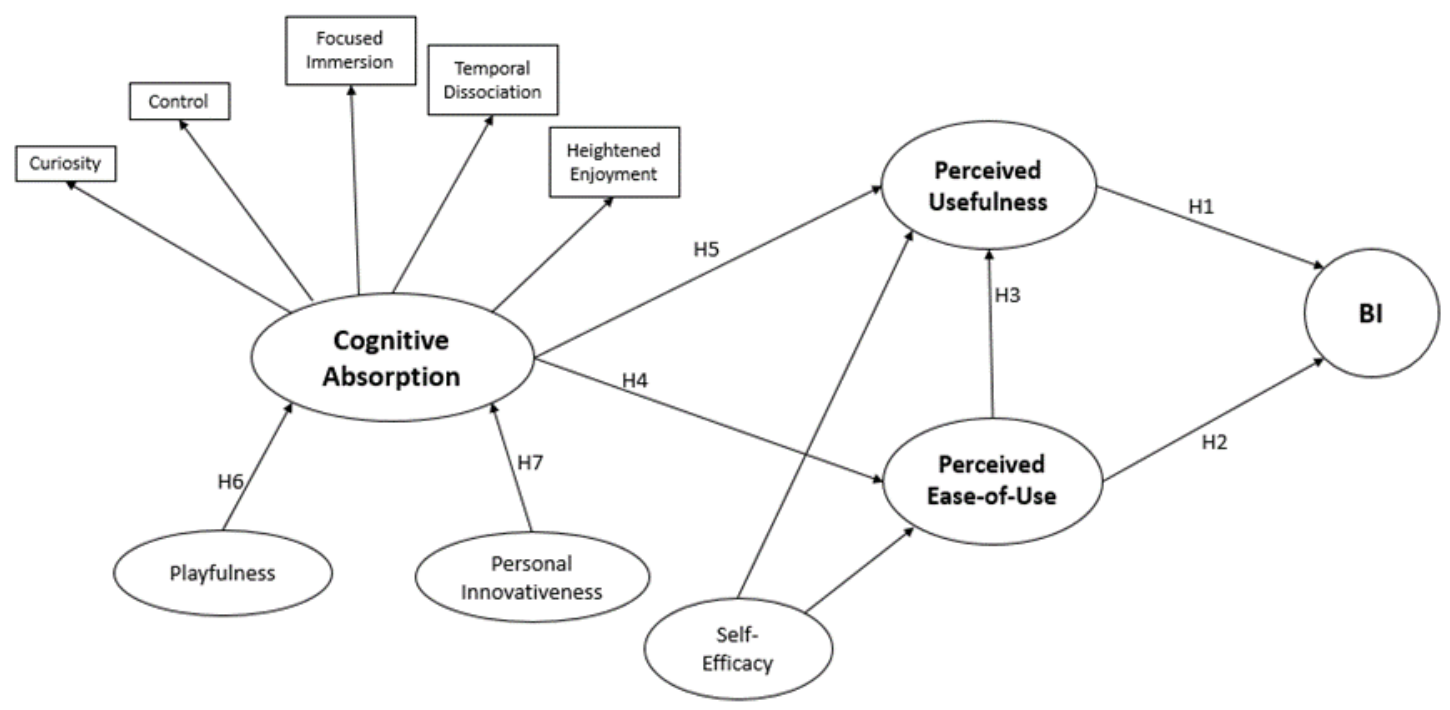

Figure 1: Nomological net

\begin{tabular}{|l|l|}
\hline \multicolumn{2}{|c|}{ Table 1. Hypotheses } \\
\hline H1 & $\begin{array}{l}\text { Perceived usefulness of social media has a positive effect on behavioral intention to use social } \\
\text { media. }\end{array}$ \\
\hline H2 & $\begin{array}{l}\text { Perceived ease of use of social media has a positive effect on behavioral intention to use social } \\
\text { media. }\end{array}$ \\
\hline H3 & $\begin{array}{l}\text { Perceived ease of use of social media has a positive effect on the perceived usefulness of the use } \\
\text { of social media. }\end{array}$ \\
\hline H4 & $\begin{array}{l}\text { After controlling for self-efficacy perceptions, cognitive absorption with social media has a positive } \\
\text { effect on the perceived ease of use of the social media. }\end{array}$ \\
\hline H5 & $\begin{array}{l}\text { After controlling for self-efficacy perceptions, cognitive absorption with social media has a positive } \\
\text { effect on the perceived usefulness of the social media. }\end{array}$ \\
\hline H6 & Computer playfulness has a positive effect on cognitive absorption with social media. \\
\hline H7 & Personal innovativeness has a positive effect on cognitive absorption with social media. \\
\hline
\end{tabular}

\section{Methodology}

To prepare the scales for the social media context, we made small adjustments in the items, replacing the word Web for social media (see Appendix B). The self-efficacy scale required a few more edits for the new context. In all cases, we retained the original meaning of the items, and only changed words to reflect the new setting. Based on the original study, we applied reverse scales for the same three elements (FI4R, CO2R, and PIIT2R) used by Agarwal and Karahanna (2000). However, we also noticed that the item HE4 (Using the social media bores me) was indeed a reverse scale, for some reason not reversed in the original paper. Thus, in other to correctly use it, we modified the scale to HE4R. All items, except those for selfefficacy, used a seven-point Likert scale, ranging from $1=$ strongly disagree to $7=$ strongly agree. Selfefficacy was measured using a 10-item response set having as anchors 1 for "Not at all confident" and 10 for "Very confident."

Using the Qualtrics platform, a total of 389 questionnaires were electronically forwarded to undergraduate students of a large state university, in the southwest of the United States. By email, they were invited to participate and instructed to respond to the questionnaire honestly. To ensure that they were answering the questions, we added three attention check questions. In the end, 27 responses, out of the 326 received, had missing or incomplete responses, leaving 299 valid ones. As recommended by The European Social Survey Education Net, we should discard respondents who gave the same answer in more than $80 \%$ of the questionnaire, since such answers would not reflect their actual responses. We then eliminated 5 students amongst the 299 valid responses because of low-quality level responses (same answer in more than $80 \%$ of the questions) they had offered. In the end, from a total of 389 valid responses, we collected 294, a response rate of $76 \%$. 
Table 2 compares the sample characteristics from the original study and our replication, and while in the first gender and age distribution are quite similar, in the second, people are more experienced in the use of technology, which is not a surprise if we considering the time passed between both studies.

\begin{tabular}{|c|c|c|c|c|}
\hline \multicolumn{5}{|c|}{ Table 2: Sample Characteristics } \\
\hline & \multicolumn{2}{|c|}{ Agarwal \& Karahanna (2000) } & \multicolumn{2}{|c|}{ Replication Study } \\
\hline & Mean & Std. Deviation & Mean & Std. Deviation \\
\hline Age & 22.90 & 4.14 & 21.53 & 3.22 \\
\hline PC Experience & 7.27 & 3.45 & 11.38 & 3.76 \\
\hline Social Media Experience & - & - & 7.57 & 1.73 \\
\hline Web Experience & 3.76 & 1.54 & -- & \\
\hline Gender & Male & 153 & Male & 158 \\
\hline & Female & 117 & Female & 136 \\
\hline
\end{tabular}

\section{Results}

As in the original study, we analyzed data using partial least squares structural equation modeling. We also used SmartPLS (version 2.0) to assess measurement and structural models in a two-stage approach. First, we analyzed the measurement model starting with the confirmatory factor analysis. Second, we analyzed the structural model using the factor scores for the second-order factor of CA. Table 3 shows the descriptive statistics for the research constructs, where Behavioral Intention, Perceived Usefulness, Perceived Ease of Use, Self Efficacy, Temporal Dissociation, and Curiosity presented a slightly higher standard deviation than in the study performed by Agarwal and Karahanna (2000). In the replication study, we have found a higher self-efficacy mean compared to the original research, emphasizing the fact that nowadays people feel more comfortable with technology.

\begin{tabular}{|l|c|c|c|c|}
\hline \multicolumn{5}{|c|}{ Table 3: Descriptive Statistics } \\
\hline \multicolumn{1}{|c|}{ Construct } & Mean & Std. Deviation & Mean & Std. Deviation \\
\hline Behavioral Intention (BI) & 6.35 & 1.07 & 5.70 & 1.24 \\
\hline Perceived Usefulness (PU) & 5.43 & 1.01 & 3.60 & 1.28 \\
\hline Ease of Use (PEOU) & 5.34 & 1.03 & 5.45 & 1.11 \\
\hline Self Efficacy (SE) & 7.32 & 1.70 & 8.36 & 1.21 \\
\hline Playfulness (CPS) & 4.69 & 1.04 & 4.59 & 1.10 \\
\hline Personal Innovativeness (PIIT) & 4.87 & 1.07 & 3.97 & .94 \\
\hline CA: Temporal Dissociation (TD) & 5.36 & 1.18 & 5.40 & 1.33 \\
\hline CA: Focused Immersion (FI) & 4.76 & .98 & 4.37 & .95 \\
\hline CA: Heightened Enjoyment (HE) & 5.15 & 1.06 & 4.63 & .80 \\
\hline CA: Control (CO) & 5.33 & .93 & 3.98 & .89 \\
\hline CA: Curiosity (CU) & 4.93 & 1.04 & 4.74 & 1.20 \\
\hline
\end{tabular}

\subsection{Measurement Model}

To assess the psychometric properties of the scales, we analyzed the convergent validity regarding Average Variance Extracted (AVE) and item loadings, the discriminant validity through the cross-loadings and the square root of the AVE, and also internal consistency through composite reliability scores.

By analyzing the AVE of the model constructs and all their respective items, we identified that the Focused Immersion, Control, and Self-Efficacy constructs presented an AVE lower than 0.5. On average, that indicates more error in the items than in the variance explained by the construct (Hair et al., 2014). For that 
reason, to ensure the convergent validity of the model, one by one, we eliminated the items with lower factor loadings (FI_4R; CO_2R; SE_2; SE_1) until we confirmed that the AVE was greater than or equal to 0.5. Agarwal and Karahanna (2000) maintained all items once they found AVE > 0.5 in all constructs.

The second evaluation phase of the measurement model included the analysis of the discriminant validity. In the analysis of the cross-loadings, the PIIT_2R indicator was the only one that showed problems, once it was verified the presence of cross-loadings exceeding outer load of PIIT_2R. With the objective of attaining discriminant validity through the analysis of cross-loadings, we eliminated the PIIT $2 R$ indicator. The other items were appropriately loaded as presented in the factor analysis table in Appendix A. As for the FornellLarcker criterion; the model obtained discriminant validity because the square root of each AVE of the construct was more significant than the correlations between the other latent variables (Fornell and Larcker, 1981). Concerning internal consistency, the results of the composite reliability were higher than 0.8 , considered satisfactory by Hair et al. (2014). Table 4 shows the results of the AVE and discriminant validity of the construct.

\begin{tabular}{|l|c|c|c|c|c|c|c|c|c|c|c|c|c|}
\hline \multicolumn{10}{|c|}{ Table 4: Discriminant Validity and AVE Results } \\
\hline & AVE & $\begin{array}{c}\text { Composite } \\
\text { Reliability }\end{array}$ & BI & PU & PEOU & SE & CPS & PIIT & TD & FI & HE & CO & CU \\
\hline BI & 0.88 & 0.96 & $\mathbf{0 . 9 4}$ & & & & & & & & & & \\
\hline PU & 0.67 & 0.89 & 0.18 & $\mathbf{0 . 8 2}$ & & & & & & & & & \\
\hline PEOU & 0.74 & 0.92 & 0.61 & 0.15 & $\mathbf{0 . 8 6}$ & & & & & & & & \\
\hline SE & 0.52 & 0.90 & 0.13 & 0.00 & 0.19 & $\mathbf{0 . 7 2}$ & & & & & & & \\
\hline CPS & 0.66 & 0.93 & 0.49 & 0.39 & 0.43 & 0.09 & $\mathbf{0 . 8 1}$ & & & & & & \\
\hline PIIT & 0.77 & 0.91 & 0.17 & 0.44 & 0.32 & 0.10 & 0.50 & $\mathbf{0 . 8 8}$ & & & & & \\
\hline TD & 0.77 & 0.94 & 0.61 & 0.06 & 0.57 & 0.16 & 0.33 & 0.18 & $\mathbf{0 . 8 8}$ & & & & \\
\hline FI & 0.60 & 0.85 & 0.31 & 0.16 & 0.41 & 0.13 & 0.30 & 0.16 & 0.56 & $\mathbf{0 . 7 7}$ & & & \\
\hline HE & 0.72 & 0.91 & 0.66 & 0.30 & 0.58 & 0.06 & 0.51 & 0.24 & 0.57 & 0.40 & $\mathbf{0 . 8 5}$ & & \\
\hline CO & 0.68 & 0.81 & 0.34 & 0.28 & 0.44 & 0.06 & 0.44 & 0.23 & 0.30 & 0.27 & 0.43 & $\mathbf{0 . 8 3}$ & \\
\hline CU & 0.74 & 0.90 & 0.48 & 0.32 & 0.45 & 0.09 & 0.62 & 0.34 & 0.30 & 0.34 & 0.67 & 0.43 & $\mathbf{0 . 8 6}$ \\
\hline
\end{tabular}

\subsection{Structural Model}

The structural model was analyzed through the significance of the relationships and the $\mathrm{R}^{2}$ (coefficient of determination). Perceived Usefulness and Perceived Ease of Use account for $38.3 \%$ of the variance in Behavioral Intention. Both Cognitive Absorption and Self-Efficacy explain $44.1 \%$ of the variance in Perceived Ease of Use, while Cognitive Absorption, Self-Efficacy and Perceived Ease of use refer to $12.9 \%$ in Perceived Usefulness, and $46 \%$ in the original study. Such relevant difference may be attributed to the fact that social media is focused on enjoyment and social relationship rather than elements in performance, productivity, and effectiveness. In fact, the Web seems to be more useful for instrumental outcomes than social media, and therefore likely to explain the value of $46 \%$. Playfulness and Personal Innovativeness describe $37 \%$ of the variance in Cognitive Absorption. Generally speaking, compared to the results found by Agarwal and Karahanna (2000), the results of the $R^{2}$ values found in this replication were inferior. Table 5 compares the results of both studies.

\begin{tabular}{|l|c|c|}
\hline \multicolumn{2}{|c|}{ Table 5: Comparing R $\mathbf{R}^{2}$ results Original and Replication Study } \\
\hline \multicolumn{1}{|c|}{$\mathbf{R}^{\mathbf{2}}$} & $\begin{array}{c}\text { Agarwal \& } \\
\text { Karahanna (2000) }\end{array}$ & $\begin{array}{c}\text { Replication } \\
\text { Study }\end{array}$ \\
\hline Perceived Ease of Use + Perceived Usefulness $\rightarrow$ Behavioral Intention & $48 \%$ & $38.3 \%$ \\
\hline Cognitive Absorption + Self-Efficacy $\rightarrow$ Perceived Ease of Use & $46 \%$ & $44.1 \%$ \\
\hline $\begin{array}{l}\text { Cognitive Absorption + Self-Efficacy + Perceived Ease of Use } \rightarrow \text { Perceived } \\
\text { Usefulness }\end{array}$ & $46.2 \%$ & $12.9 \%$ \\
\hline Playfulness + Personal Innovativeness $\rightarrow$ Cognitive Absorption & $42.1 \%$ & $37 \%$ \\
\hline
\end{tabular}


From the seven hypotheses proposed by Agarwal and Karahanna (2000), six were supported, but in our study only five. Table 6 summarizes the hypothesis, while table 7 shows the test results. Hypothesis 1 , which states that Perceived Usefulness has a positive effect on Behavioral Intention, was supported, as shown in Figure 2. Hypothesis 2 (Perceived Ease of Use -> Behavioral Intention) was significant at 0.001. Hypothesis 3 was not supported in the replication study, and the same happened in the original research, and the study conducted by Davis (1989). As in the Agarwal and Karahanna study (2000), hypotheses 4 and 5 were supported, showing that Cognitive Absorption is a significant predictor of Perceived Usefulness and Perceived Ease of Use. Regarding the predictors of CA, Playfulness and Personal Innovativeness, only the former had substantial effects on CA (H6), having the latter $(\mathrm{H} 7)$ not supported.

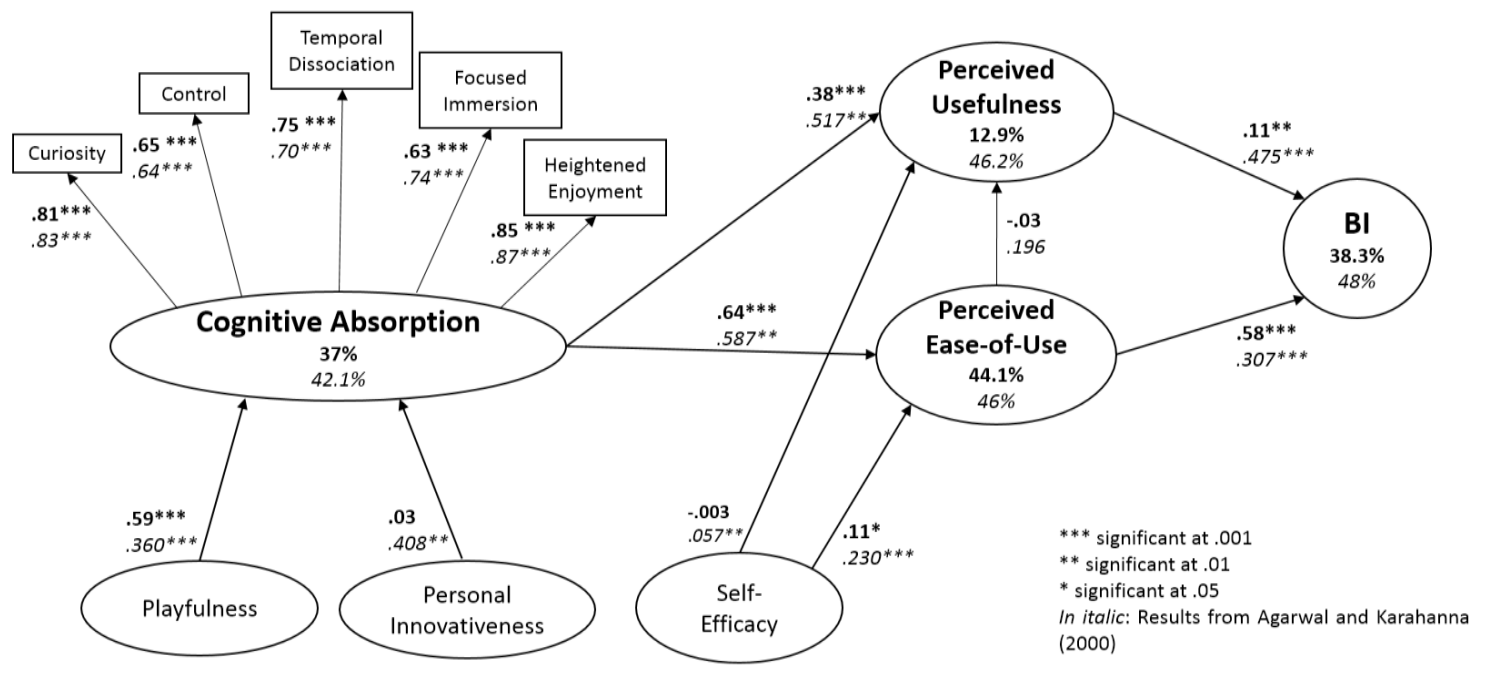

Figure 2: PLS Results from Replication study and Agarwal and Karahanna (2000)

\begin{tabular}{|l|c|c|}
\hline \multicolumn{2}{|c|}{ Table 6. Summary of Hypothesis Tests } \\
\hline \multicolumn{1}{|c|}{ Hypothesis } & $\begin{array}{c}\text { Agarwal and } \\
\text { Karahanna (2000) }\end{array}$ & $\begin{array}{c}\text { Replication } \\
\text { study }\end{array}$ \\
\cline { 2 - 3 } & Support & Support \\
\hline H1: Perceived Usefulness -> Behavioral Intention & Yes & Yes \\
\hline H2: Perceived Ease of Use -> Behavioral Intention & Yes & Yes \\
\hline H3: Perceived Ease of Use -> Perceived Usefulness & No & Yes \\
\hline H4: Cognitive Absorption -> Perceived Ease of Use & Yes & Yes \\
\hline H5: Cognitive Absorption -> Perceived Usefulness & Yes & Yes \\
\hline H6: Playfulness -> Cognitive Absorption & Yes \\
\hline H7: Personal Innovativeness -> Cognitive Absorption & Yes & No \\
\hline
\end{tabular}

Agarwal and Karahanna (2000) executed additional analysis, adding a direct path from Cognitive Absorption to Behavioral Intention and found that the direct path was significant and increased the $\mathrm{R}^{2}$ of Behavioral Intention from $48 \%$ to $50.7 \%$. We also tested such effect, and the $\mathrm{R}^{2}$ rose from $38.3 \%$ to $49.3 \%, 11 \%$ higher when compared to the $2 \%$ achieved in the original study. Figure 3 illustrates the results, including the direct path from Cognitive Absorption to Behavioral Intention. 


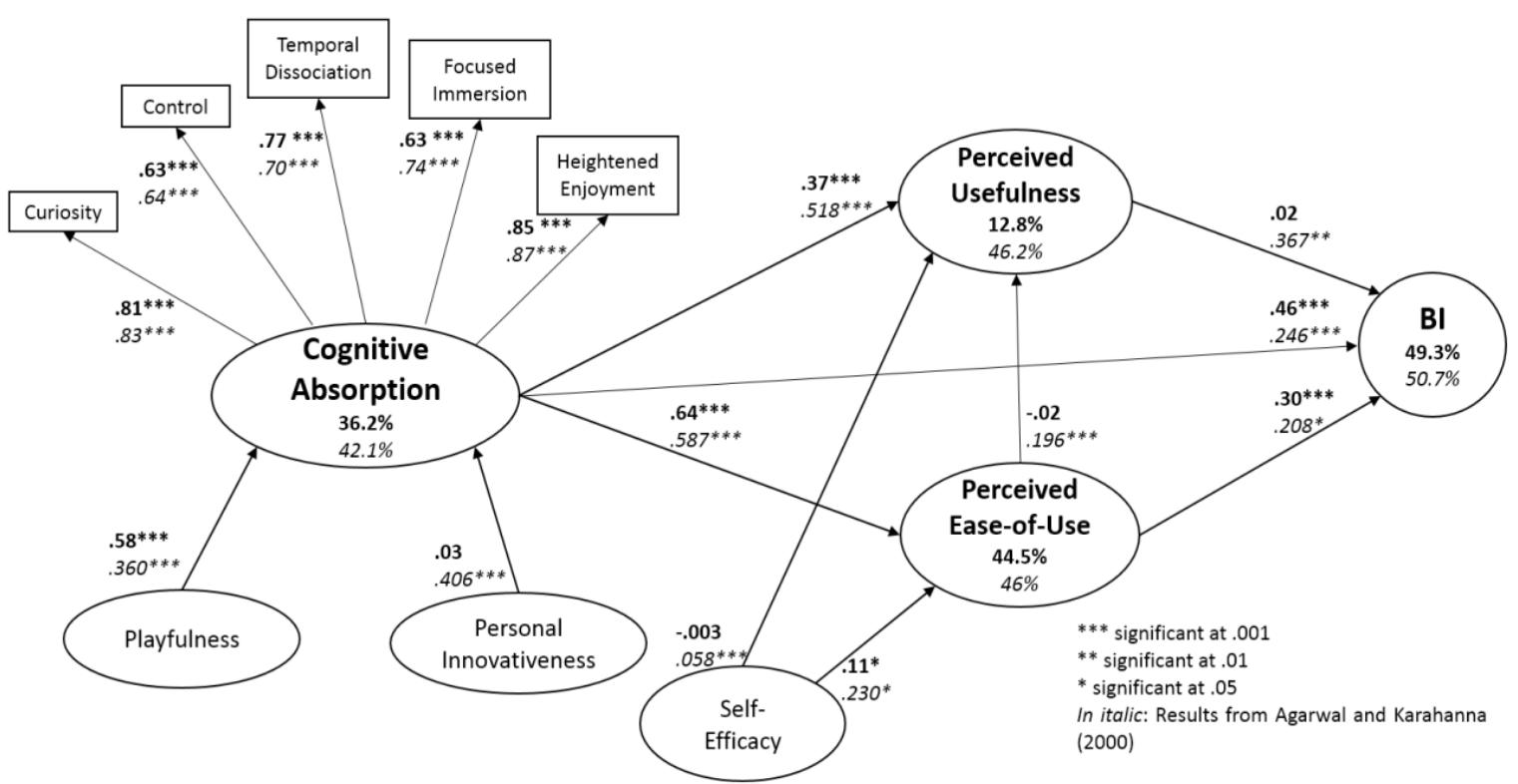

Figure 3: PLS Results (with direct effects) from Replication study and Agarwal and Karahanna (2000)

\section{Discussion}

In this study, our goal was to replicate the original paper from Agarwal and Karahanna (2000), by testing the model and the concept of cognitive absorption in a social media context. To adjust the study to such context, we replaced some words in the scale to reflect the new setting, but we precisely followed the methodological procedure as it was conceived. Despite the many technological advances that occurred during the sixteen years elapsing between the studies, our findings evidenced significant similarities, and it also disclosed some intriguing differences discussed next as well.

First, the hypothesis 3, which postulated that perceived ease of use would influence perceived usefulness, was supported neither by this replication nor by the original study. According to our findings, there is no relation between the PEOU of social media and the instrumental outcomes measured by PU. In other words, the perceived ease of use (PEOU) does not influence the perceived usefulness (PU), since the PU measures focus on productivity, effectiveness, and performance. As in the original research, the $\mathrm{H} 3$ was not supported, considering that PEOU of using the Web does not necessarily mean PU as well. Although those findings are in line with the TAM theory (Davis, 1989), Midha (2016) recently replicated the study by Agarwal and Karahanna (2000) in the Second life context and found that PEOU positively influences PU. In the research conducted by Midha (2016), that result was associated with the complexity of the Second Life platform, which did not take place in the web environment in Agarwal and Karahanna (2000) study, neither in the social media context of this replication. We suppose that the differences in our findings arise from the characteristics of the social media environment that typically is a user-friendly platform often related to the pleasure of meeting friends, having social interaction, and briefly resting from work.

Second, another highlight to be made concerns the personal experience of each studied population. The original study was published in 2000, in the late 1990s, and it investigated the web context. On the other hand, our replication involved a current sample comprising students who have been exposed to technology since their childhood. Indeed, most of those students could be referred to as digital natives. Thus, it is plausible to assume a different perception of "Ease of Use" between today and sixteen years ago and the presence of an intuitive and user-friendly technology that became the norm, and therefore, less critical.

Third, all coefficients of determination found in our replication were lower than those in the original study; however, the most relevant case relates the perceived usefulness construct, where we found an $\mathrm{R}^{2}$ of $12.9 \%$, while in the original paper that was $46.2 \%$. In the original study, PU is positively influenced by CA and self-efficacy, which may explain such divergence, whereas in our replication PU is revealed only by CA. Hence, considering that we are studying a different context, it is possible to presume that social media is more related to playfulness and relationships than to enhance performance or productivity. People tend to 
use social media to take a mental break from the job (Duggan et al., 2016) and not to improve instrumental outcomes to have a better performance in college.

Fourth, hypothesis 7, which points that personal innovativeness (willingness to try out any new technology) would influence cognitive absorption, was supported in the original paper, but not in the present replication. We presume that this hypothesis has not been confirmed because individuals with traits of innovativeness are more discerning about which new information technology would be more advantageous to spend time and attention. Compared to the 1990s, period of the original study, new ITs currently bombard us on a daily basis, in the social networks, gadgets, smartphones, and so on, making it unfeasible to test everything that is new. Having that in view, the average of 4.87 in PIIT in the original study and 3.97 in this replication means that in the present context users are less likely to try any new technology, considering the abundance of such ITs.

Fifth, the direct path from $\mathrm{CA}$ to $\mathrm{BI}$ was tested in both studies with different results. While in the original paper the increases in the immediate path explained variance in $\mathrm{BI}$ of just $2 \%$, in our replication it reported an increase of $11 \%$. Based on that, we may imply that CA is an even more critical antecedent of $\mathrm{BI}$ in the social media context when compared to the Web context. A likely reason might be bound to the power social media has in holding the attention of individuals, facilitating social interaction, and maintaining them connected for a long time. Many have admitted being addicted to social media, and it sure indicates a valuable issue for future studies. Considering the growing number of social media year by year, we believe that studies investigating individuals of different gender, location, age, and intellectual level is a relevant research topic in IS field, where the CA construct would undoubtedly provide the theoretical base.

Finally, in the conclusion of the original paper, Agarwal and Karahanna (2000) remarked that pleasure and enjoyment would be significant predictors of usage intention in the future. Our replication provides some evidence to support their argument since the use of social media context regards much more the pleasure and enjoyment of the social environment than to the usefulness for productivity and performance. Furthermore, we would suggest that future studies investigated how the Agarwal and Karahanna (2000) model works in a professional social media context, such as the Linkedln. In that environment, users are mostly professionals from different areas, levels, and organizations, concerned with building or maintaining their networking to achieve better professional outcomes, rather than using it for enjoyment or for briefly resting from work.

\section{Conclusion}

Sixteen years after the Agarwal and Karahanna study, this methodological replication renders evidence that the Cognitive Absorption construct is comprised of five dimensions named Curiosity, Control, Focused Immersion, Temporal Dissociation and Heightened Enjoyment. Regarding the two personality traits mentioned as antecedents Cognitive Absorption, only playfulness was significant, since individuals at a playful cognitive state are also likely to experience a state of cognitive absorption. Moreover, statistics concerning the personality trait on the willingness to experience any new technology (Personal Innovativeness) were not significant. Behind that, we found that in a setting where a substantial amount of new technologies is presented to the user, the core conception relates more to experience new technology, already known by others, other than being the first to explore it.

Finally, despite all changes in technology and the time elapsed Agarwal and Karahanna (2000) have published their study, the cognitive absorption construct, and this nomological net have proven to be quite useful and valid when applied in a social media context.

\section{Acknowledgments}

We sincerely would like to thank the editors and reviewers of the Association for Information Systems Transactions on Replication Research for their valuable contribution to improving the quality of this paper 


\section{References}

Agarwal, R., \& Karahanna, E. (2000). Time flies when you're having fun: Cognitive absorption and beliefs about information technology usage. MIS Quarterly, 24(4), 665-694.

Agnihotri, R., Kothandaraman, P., Kashyap, R., \& Singh, R. (2012). Bringing "social" into sales: The impact of salespeople's social media use on service behaviors and value creation. Journal of Personal Selling and Sales Management, 32(3), 333-348.

Ali, H. (2011). Exchanging value within individuals' networks: Social support implications for health marketers. Journal of Marketing Management, 27(3-4), 316-335.

Boyd, D., \& Ellison, N. (2007). Social network sites: Definition, history, and scholarship. Journal of Computer-Mediated Communication, 13(1), 210-30.

Chandra, S., Srivastava, S., \& Theng, Y. (2012). Cognitive absorption and trust for workplace collaboration in virtual worlds: An information processing decision making perspective. Journal of the Association for Information Systems, 13(October 2012), 797-835.

Csikszentmihalyi, M. (1990). Flow: the psychology of optimical experience. New York: Harper \& Row.

De Vries, L., Gensler, S., \& Leeflang, P. S. H. (2012). Popularity of brand posts on brand fan pages: An investigation of the effects of social media marketing. Journal of Interactive Marketing, 26(2), 83-91.

Duggan, M., Ellison, N. B., Lampe, C., Lenhart, A., \& Madden, M. (2015, January 9). Social media update 2014. Pew Research Center. Retrieved from http://www.pewinternet.org/2015/01/09/social-mediaupdate-2014/

Duggan, M., Page, D., \& Manager, S. C. (2016, November 11). Social Media Update 2016. Pew Research Center. Retrieved from http://www.pewinternet.org/2016/11/11/social-media-update-2016/

Hajli, M. N. (2014). A study of the impact of social media on consumers. International Journal of Market Research, 56(January), 387-404.

Midha, V. (2016). Cognitive absorption an empirical examination of 3-D immersive virtual world users. Transactions on Replication Research, 2, 1-11.

Pfeil, U., Arjan, R., \& Zaphiris, P. (2009). Age differences in online social networking - A study of user profiles and the social capital divide among teenagers and older users in MySpace. Computers in Human Behavior, 25(3), 643-654.

Saadé, R., \& Bahli, B. (2005). The impact of cognitive absorption on perceived usefulness and perceived ease of use in on-line learning: An extension of the technology acceptance model. Information \& Management, 42(2), 317-327.

Tellegen, A. (1982). Brief manual for the differential personality questionnaire. Unpublished Manuscript, 1010-1031.

Tellegen, A., \& Atkinson, G. (1974). Openness to absorbing and self-altering experiences ("absorption"), a trait related to hypnotic susceptibility. Journal of Abnormal Psychology, 83(3), 268-277.

The European Social Survey Education Net (2013). The first round of preparation, cleaning, and recoding. Retrieved from: <http://essedunet.nsd.uib.no/cms/topics/1/4/2.html>.

Webster, J., \& Ho, H. (1997). Audience engagement in multimedia presentations. ACM SIGMIS Database, 28(2), 63-77.

Wu, J. J., Chen, Y. H., \& Chung, Y. S. (2010). Trust factors influencing virtual community members: A study of transaction communities. Journal of Business Research, 63(9-10), 1025-1032. 


\section{Appendix A: Factorial Analysis}

\begin{tabular}{|c|c|c|c|c|c|c|c|c|c|c|c|c|c|c|c|c|c|c|c|c|c|c|}
\hline & \multicolumn{2}{|c|}{$\mathrm{BI}$} & \multicolumn{2}{|c|}{ PU } & \multicolumn{2}{|c|}{ PEOU } & \multicolumn{2}{|c|}{ SE } & \multicolumn{2}{|c|}{ CPS } & \multicolumn{2}{|c|}{ PIIT } & \multicolumn{2}{|c|}{ TD } & \multicolumn{2}{|c|}{$\mathrm{FI}$} & \multicolumn{2}{|c|}{$\mathrm{HE}$} & \multicolumn{2}{|c|}{$\mathrm{CO}$} & \multicolumn{2}{|c|}{$\mathrm{CU}$} \\
\hline BI_1 & .94 & & .59 & .19 & .54 & .56 & .17 & .09 & .27 & 0.45 & .31 & .18 & .46 & .57 & 0.3 & .28 & .51 & .59 & .48 & .33 & .4 & .42 \\
\hline BI_2 & .96 & .95 & .59 & .13 & .51 & .61 & .18 & .08 & .25 & 0.45 & .34 & .14 & .46 & .6 & 0.3 & .32 & .53 & .63 & .48 & .33 & .4 & .49 \\
\hline BI_3 & .96 & .94 & .65 & .2 & .56 & .55 & .15 & .12 & .29 & 0.49 & .36 & .16 & .46 & .56 & 0.31 & .29 & .57 & .63 & .53 & .3 & .42 & .45 \\
\hline PU_1 & .4 & .06 & .72 & .87 & .45 & .05 & .21 & -.03 & .4 & 0.28 & .4 & .4 & .36 & 0 & 0.34 & .12 & .53 & .19 & .43 & .2 & .47 & .25 \\
\hline PU_2 & .6 & -.06 & .93 & .72 & .53 & -.1 & .19 & -.04 & .38 & 0.23 & .38 & .27 & .34 & -.14 & 0.31 & .02 & .54 & .1 & .48 & .19 & .5 & .09 \\
\hline PU_3 & .68 & .34 & .9 & .84 & .45 & .32 & .25 & .01 & .33 & 0.42 & .41 & .38 & .37 & .21 & 0.29 & .2 & .52 & .4 & .53 & .29 & .46 & .38 \\
\hline PU_4 & .53 & .03 & .91 & .84 & .37 & -.03 & .21 & -.04 & .33 & 0.26 & .39 & .35 & .34 & -.06 & 0.29 & .1 & .47 & .12 & .44 & .21 & .48 & .19 \\
\hline PEOU_1 & .48 & .54 & .39 & .03 & .86 & .85 & .34 & .28 & .26 & 0.3 & .47 & .17 & .22 & .46 & 0.28 & .27 & .41 & .49 & .56 & .39 & .29 & .37 \\
\hline PEOU_2 & .35 & .44 & .38 & .21 & .71 & .78 & .22 & .26 & .3 & 0.36 & .27 & .3 & .19 & .41 & 0.28 & .31 & .39 & .39 & .5 & .33 & .29 & .34 \\
\hline PEOU_3 & .51 & .53 & .5 & .14 & .86 & .89 & .3 & .26 & .34 & 0.43 & .49 & .35 & .3 & .52 & 0.37 & .42 & .49 & .54 & .62 & .43 & .41 & .41 \\
\hline PEOU_4 & .54 & .57 & .54 & .13 & .9 & .9 & .35 & .26 & .31 & 0.37 & .48 & .27 & .32 & .56 & 0.37 & .39 & .55 & .54 & .6 & .37 & .42 & .41 \\
\hline SE_1 & .09 & .04 & .14 & .06 & .27 & .21 & .74 & .59 & .08 & .15 & .32 & .22 & .03 & .07 & 0.1 & .01 & .1 & .05 & .19 & .03 & .14 & .07 \\
\hline SE_2 & .05 & -.11 & .18 & .05 & .25 & .08 & .73 & .55 & .1 & .03 & .29 & .17 & .05 & -.01 & .06 & .01 & .07 & .01 & .14 & .02 & .16 & .02 \\
\hline SE_3 & .12 & .04 & .11 & .01 & .2 & .24 & .76 & .68 & .13 & -.03 & .36 & .14 & .03 & .05 & .05 & .01 & .11 & .12 & .22 & .09 & .18 & .09 \\
\hline SE_4 & .16 & .08 & .19 & -.04 & .29 & .25 & .82 & .74 & .18 & -.07 & .34 & .1 & .06 & .11 & .16 & .03 & .2 & .08 & .19 & .03 & .24 & .02 \\
\hline SE_5 & .15 & .04 & .24 & -.02 & .32 & .22 & .76 & .74 & .08 & -.01 & .26 & .12 & -.01 & .05 & .11 & -.05 & .14 & .07 & .14 & -.02 & .12 & 0 \\
\hline SE_6 & .1 & .07 & .16 & -.06 & .29 & .23 & .32 & .75 & .03 & 0.06 & .03 & .12 & .03 & .02 & .03 & -.04 & .09 & .04 & 0.1 & .07 & .02 & .03 \\
\hline SE_7 & .18 & 0.1 & .07 & .04 & .11 & .19 & .8 & .71 & .21 & 0.06 & .31 & .2 & .1 & .16 & .15 & .1 & .22 & .11 & .27 & .05 & .16 & .03 \\
\hline SE_8 & .06 & .07 & .26 & .04 & .33 & .17 & .7 & .67 & .12 & 0.08 & .26 & .2 & .13 & .06 & .15 & .03 & .13 & .08 & .14 & .05 & .17 & .06 \\
\hline SE_9 & .15 & .09 & .17 & -.02 & .22 & .22 & .63 & .71 & .12 & -.01 & .19 & .08 & .01 & .04 & -.01 & -.02 & .07 & .04 & .2 & .05 & .04 & .03 \\
\hline SE_10 & .16 & .1 & .18 & -.1 & .25 & .24 & .7 & .76 & .14 & .04 & .25 & .14 & -.01 & .1 & .11 & .01 & .11 & .05 & .22 & -.01 & .08 & .02 \\
\hline CPS_1 & .27 & .38 & .35 & .35 & .31 & .28 & .2 & .02 & .76 & 0.8 & .39 & .46 & .3 & .28 & .31 & .24 & .42 & .37 & .19 & .31 & .48 & .46 \\
\hline CPS_2 & .26 & .41 & .37 & .28 & .29 & .36 & .1 & -.01 & .87 & 0.86 & .37 & .37 & .27 & .3 & 0.34 & .24 & .41 & .44 & .21 & .39 & .56 & .62 \\
\hline CPS_3 & .29 & .37 & .39 & .32 & .38 & .42 & .16 & .1 & .75 & 0.72 & .27 & .39 & .31 & .24 & 0.38 & .18 & .44 & .37 & .29 & .38 & .42 & .44 \\
\hline CPS_4 & .24 & .41 & .37 & .31 & .25 & .42 & .12 & -.02 & .91 & 0.86 & .37 & .44 & .27 & .3 & 0.34 & .25 & .41 & .47 & .19 & .35 & .51 & .53 \\
\hline CPS_5 & .17 & .47 & .27 & .33 & .24 & .3 & .15 & 0 & .8 & 0.79 & .36 & .38 & .33 & .29 & 0.31 & .25 & .42 & .49 & .1 & .33 & .45 & .52 \\
\hline CPS_6 & .2 & .36 & .28 & .31 & .32 & .33 & .14 & .07 & .83 & 0.8 & .35 & .37 & .25 & .22 & 0.32 & .25 & .37 & .34 & .22 & .38 & .38 & .42 \\
\hline
\end{tabular}




\begin{tabular}{|c|c|c|c|c|c|c|c|c|c|c|c|c|c|c|c|c|c|c|c|c|c|c|}
\hline \multirow[b]{2}{*}{ CPS_7 } & \multicolumn{2}{|c|}{$\mathrm{BI}$} & \multicolumn{2}{|c|}{$\mathrm{PU}$} & \multicolumn{2}{|c|}{ PEOU } & \multicolumn{2}{|c|}{ SE } & \multicolumn{2}{|c|}{ CPS } & \multicolumn{2}{|c|}{ PIIT } & \multicolumn{2}{|c|}{ TD } & \multicolumn{2}{|c|}{$\mathrm{Fl}$} & \multicolumn{2}{|c|}{$\mathrm{HE}$} & \multicolumn{2}{|c|}{$\mathrm{CO}$} & \multicolumn{2}{|c|}{$\mathrm{CU}$} \\
\hline & & .39 & .33 & .33 & .31 & .34 & .16 & -.01 & .84 & 0.85 & .34 & .42 & .18 & .25 & 0.24 & .26 & .34 & .43 & .23 & .35 & .41 & .52 \\
\hline PIIT_1 & & .16 & .36 & .37 & .36 & .3 & .26 & .17 & .34 & 0.45 & .83 & .92 & .28 & .19 & 0.31 & .14 & .41 & .23 & .28 & .23 & .44 & .3 \\
\hline PIIT_2R & .31 & .12 & .34 & .04 & .45 & .21 & .3 & .20 & .32 & .13 & .77 & .43 & .22 & .08 & .32 & -.01 & .41 & .14 & .33 & -.09 & .28 & .03 \\
\hline PIIT_3 & .02 & .02 & .21 & 0.4 & .32 & .16 & .34 & .15 & .25 & .38 & .7 & .78 & .08 & .07 & .29 & .1 & .31 & .09 & .17 & .13 & .29 & .19 \\
\hline PIIT_4 & .36 & .22 & .5 & .39 & .51 & .35 & .33 & .19 & .42 & .47 & .88 & .92 & .3 & .19 & .41 & .16 & .47 & .29 & .38 & .24 & .49 & .38 \\
\hline TD_1 & .38 & .52 & .34 & .11 & .27 & .51 & .05 & .15 & .32 & .29 & .24 & .17 & .87 & .91 & .46 & 0.5 & .53 & .5 & .17 & .26 & .51 & .4 \\
\hline TD_2 & .47 & .55 & .42 & .04 & .32 & .54 & .13 & .08 & .33 & .27 & .27 & .12 & .84 & .87 & .42 & .51 & .56 & .53 & .24 & .29 & .49 & .44 \\
\hline TD_3 & .43 & .51 & .39 & .03 & .33 & .5 & .07 & .14 & .34 & .28 & .28 & .14 & .9 & .87 & .48 & .52 & .6 & .48 & .24 & .27 & .55 & .44 \\
\hline TD_4 & .39 & .56 & .26 & .03 & .21 & .5 & .03 & .04 & .17 & 0.3 & .21 & .18 & .8 & .88 & .39 & . 48 & .36 & .49 & .13 & .26 & .37 & .41 \\
\hline TD_5 & .39 & .56 & .29 & .06 & .2 & .46 & .02 & .06 & .21 & 0.32 & .19 & .19 & .84 & .85 & .34 & .46 & .41 & .49 & .17 & .24 & .4 & .38 \\
\hline FI_1 & .3 & .13 & .29 & -.02 & .34 & .23 & .13 & .03 & .29 & 0.11 & .31 & -.01 & .29 & .35 & .82 & .67 & .42 & .23 & .36 & .13 & .41 & .17 \\
\hline FI_2 & .27 & .32 & .29 & .16 & .26 & .39 & .1 & -.03 & .35 & 0.29 & .31 & .15 & .52 & .55 & .74 & .89 & .54 & .43 & .16 & .21 & .52 & .34 \\
\hline FI_3 & .35 & .31 & .37 & .21 & .39 & .37 & .04 & .01 & .38 & 0.29 & .42 & .18 & .51 & .53 & .79 & .89 & .55 & .34 & .34 & .29 & .52 & .33 \\
\hline FI_4R & .17 & -.16 & .18 & -.09 & .24 & -.15 & .12 & -.06 & .14 & -.10 & .26 & -.06 & .18 & -.2 & .72 & -.11 & .34 & -.11 & .23 & -.17 & .2 & -.21 \\
\hline FI_5 & .14 & .12 & .23 & .07 & .29 & .23 & .14 & .08 & .25 & .16 & .32 & .12 & .34 & .21 & .81 & .61 & .38 & .17 & .25 & .19 & .43 & .14 \\
\hline HE_1 & .54 & .62 & .55 & .3 & .59 & .55 & .18 & .05 & .47 & .5 & .49 & .25 & .55 & .52 & .53 & .38 & .9 & .91 & .44 & .38 & .61 & .68 \\
\hline HE_2 & .37 & .53 & .47 & .25 & .33 & .53 & .17 & .12 & .39 & .44 & .39 & .24 & .49 & .51 & .49 & .39 & .83 & .88 & .24 & .46 & .58 & .56 \\
\hline HE_3 & .56 & .64 & .55 & .3 & .53 & .53 & .12 & .1 & .46 & .52 & .45 & .21 & .55 & .52 & .53 & .37 & .91 & .92 & .39 & .41 & .62 & .64 \\
\hline HE_4R & .51 & .41 & .48 & .1 & .46 & .29 & .18 & .09 & .39 & .21 & .42 & .06 & .44 & .35 & .44 & .16 & .86 & .65 & 0.4 & .09 & .52 & .31 \\
\hline CO_1 & .43 & .22 & .51 & .15 & .64 & .35 & .25 & .12 & .26 & .27 & .36 & .17 & .25 & .2 & .36 & .16 & .4 & .31 & .87 & .76 & .37 & .28 \\
\hline CO_2R & .31 & .06 & .26 & -.19 & .31 & .04 & .2 & .05 & .03 & -.17 & .15 & -.18 & -.01 & -.07 & .07 & -.15 & .17 & -.04 & .58 & -.24 & .12 & -.21 \\
\hline CO_3 & .48 & .33 & .49 & .29 & .61 & .39 & .18 & -.01 & .25 & .44 & .33 & .21 & .24 & .29 & .34 & .28 & .39 & .39 & .88 & .89 & .34 & .42 \\
\hline CU_1 & .37 & .44 & .49 & .25 & .37 & .44 & .18 & .05 & .51 & .52 & .47 & .29 & .52 & .44 & .52 & .33 & .61 & .64 & .33 & .36 & .91 & .9 \\
\hline CU_2 & .47 & .47 & .52 & .28 & .44 & .43 & .16 & .09 & .48 & .54 & .49 & .34 & .51 & .48 & .45 & .31 & .62 & .64 & .35 & .32 & .9 & .88 \\
\hline CU_3 & .31 & .32 & .47 & .31 & .34 & .27 & .18 & -.03 & .51 & .55 & .4 & .25 & .45 & .28 & .48 & .23 & .56 & .45 & .31 & .45 & .88 & .8 \\
\hline
\end{tabular}




\section{Appendix B: Measurement Instrument}

\section{Behavioral Intention}

BI1. I plan to use the social media in the future.

BI2. I intend to continue using the social media in the future.

BI3. I expect my use of the social media to continue in the future.

\section{Perceived Usefulness}

PU1. Using the social media enhances my effectiveness in college.

PU2. Using the social media improves my productivity.

PU3. I find the social media helpful for my college activities.

PU4. Using the social media improves my performance in college.

\section{Perceived Ease-of-Use}

PEOU1. Learning to operate the social media is easy for me.

PEOU2. I find it easy to get the social media to do what I want it to do.

PEOU3. It is easy for me to become skillful at using the social media.

PEOU4. I find the social media easy to use.

\section{Cognitive Absorption}

CPS1. When using the social media, I am Spontaneous.

CPS 2. When using the social media, I am Imaginative.

CPS3. When using the social media, I am Flexible.

CPS4. When using the social media, I am Creative.

CPS5. When using the social media, I am Playful.

CPS6. When using the social media, I am Original.

CPS7. When using the social media, I am Inventive.

\section{Personal Innovativeness}

PIIT1. If I heard about new information technology, I would look for ways to experiment with it.

PIIT2. In general, I am hesitant to try out new information technologies.

PIIT3. Among my peers, I am usually the first to try out new information technologies.

PIIT4. I like to experiment with new information technologies.

\section{Temporal Dissociation}

TD1. Time appears to go by very quickly when I am using the social media.

TD2. Sometimes I lose track of time when I am using the social media.

TD3. Time flies when I am using the social media.

TD4. Most time when I get on the social media, I end up spending more time that I had planned.

TD5. I often spend more time on the social media than I had intended.

\section{Focused Immersion}

FI1. While using the social media, I can block out most other distractions.

FI2. While using the social media, I am absorbed in what I am doing.

FI3. While on the social media, I am immersed in the task I am performing.

FI4. When on the social media, I get distracted by other attentions very easily.

FI5. While on the social media, my attention does not get diverted very easily.

\section{Heightened Enjoyment}

HE1. I have fun interacting with the social media.

HE2. Using the social media provides me with a lot of enjoyment.

HE3. I enjoy using the social media.

HE4. Using the social media bores me.

\section{Control}

C01. When using the social media, I feel in control.

CO2. I feel that I have no control over my interaction with the social media.

CO3. The social media allows me to control my computer interaction. 


\section{Curiosity}

CU1. Using the social media excites my interest.

CU2. Interacting with the social media makes me curious.

CU3. Using the social media arouses my imagination.

\section{Self-Efficacy}

Often we are told about software packages that are available to make work easier. For the following questions, imagine that you were given a new software package for some aspect of your work. It doesn't matter what this software package precisely does, only that it is intended to make your job easier and that you have never used it before.

The questions below ask you to indicate whether you could use this unfamiliar software package under a variety of conditions. For each of the conditions, please point ou whether you think you would be able to complete the work using the software package. Match either "Yes" or "No." Then, for each condition that you answered "Yes," please rate your confidence about your first judgment, by writing in a number from 1 to 10, where 1 indicates "Not at all confident," and 10 indicates "Totally confident." You may enter any number in this range.

\section{I could complete the job using the software package...}

SE1.... if there was no one around to tell me what to do as I go.

SE2. ... If I had never used a package like it before.

SE3. ... if I had only the software manuals for reference.

SE4. ... if I had seen someone else using it before trying it myself.

SE5. ... if I could call someone for help if I got stuck.

SE6. .... if someone else had helped me get started.

SE7. ... if I had a lot of time to complete the job for which the software was provided.

SE8. ... if I had just the built-in help facility for assistance.

SE9. ... if someone showed me how to do it first.

SE10. ... if I had used similar packages like this one before to do the job. 


\section{About the Authors}

Ana Lucia Tourinho holds a Ph.D. in Business Administration from Fundação Getúlio Vargas - EAESP São Paulo - Brazil, and she was a visiting scholar in the Management Information System department at the University of Arizona. Her research interests include Business Intelligence and Analytics, Business Value of IT, Information System Management, as well as, IT adoption and Behavior Theory.

Bruna Miyuki Oliveira holds a Ph.D. in Business Administration from Fundação Getúlio Vargas - EAESP - São Paulo - Brazil, and she was a visiting scholar in the Management Information System department at the University of Arizona. Her research areas include decision making in digital environments; impacts of information technologies on individuals and organizations, and consumer behavior in social media.

Copyright ( 2019 by the Association for Information Systems. Permission to make digital or hard copies of all or part of this work for personal or classroom use is granted without fee provided that copies are not made or distributed for profit or commercial advantage and that copies bear this notice and full citation on the first page. Copyright for components of this work owned by others than the Association for Information Systems must be honored. Abstracting with credit is permitted. To copy otherwise, to republish, to post on servers, or to redistribute to lists requires prior specific permission and/or fee. Request permission to publish from: AIS Administrative Office, P.O. Box 2712 Atlanta, GA, 30301-2712 Attn: Reprints or via e-mail from ais@aisnet.org. 